\title{
Energy insecurity, pollution mitigation, and renewable energy integration: prospective of wind energy in Ghana
}

\author{
Huaping Sun ${ }^{1,2} \cdot$ Abdul Razzaq Khan $^{3} \cdot$ Ahmed Bashir $^{3} \cdot$ David Ajene Alemzero $^{1} \cdot$ Qaiser Abbas $^{4} \cdot$ Hermas Abudu $^{5}$
}

Received: 5 March 2020 / Accepted: 11 June 2020 / Published online: 4 July 2020

(C) Springer-Verlag GmbH Germany, part of Springer Nature 2020

\begin{abstract}
Wind energy is seen as an important energy to sustainably meet the energy needs of Ghana. However, the industry in Ghana is yet to take off due to policy uncertainty and regulatory costs. The paper analyzed the key determinants and how they interact to impact the scaling up of wind energy in Ghana, using time series data, the vector auto regression (VAR) model from 2013 to 2019.There were four endogenous variables, grouped under policy, population growth, wind capacity, and electrification rate. The findings revealed the dynamic behavior of the variables from the VAR to a strongly significant positive correlation to deploying wind energy in Ghana. The impulse response functions (IRFs) equally exhibited a positive impact long-run trajectory growth of the variables after a shock to the system. The response of the first lags had differences of log policy and that of the log of GDP produced a curious result from the shock by taking a steady positive growth path in the short run and nosedived to a negative pathway in the long run. On the other hand, the interaction of the first differences of the lags of log wind capacity and log policy is quite instructive, as the headwind produced a negative relationship in the short run and to a positive growth path in the long run. This was anticipated, as the wind capacity installation of Ghana is expected to increase in the long run, when pipeline projects materialize.
\end{abstract}

Keywords Energy rises $\cdot$ Wind energy $\cdot$ VAR $\cdot$ Energy efficiency $\cdot$ Energy policy $\cdot$ Ghana

\section{Introduction}

Ghana is endowed with a number of renewable energy sources such as wind, solar, hydro, and biomass, which supply over $60 \%$ of the nation's energy needs. However, the country is yet to exploit these resources holistically for its economic gains.
To ensure energy security and avoid the over exploitation of resources and the economic and social benefits that come with wind energy deployment, the country has put in policies to develop wind energy for the country. Wind is the energy that can sustainably meet the growing demands of our energy needs. Ghana has a population of about 30 million people,

Responsible editor: Philippe Garrigues

David Ajene Alemzero

awelingazure@gmail.com

Huaping Sun

shp@ujs.edu.cn

Abdul Razzaq Khan

abdul.razzaq@ajku.edu.pk

Ahmed Bashir

Ahmeded_abc39@yahoo.com

Qaiser Abbas

Qabbas@gudgk.edu.pk

Hermas Abudu

hercin2013@gmail.com
1 School of Finance and Economics, Jiangsu University, Zhenjiang 212013, China

2 School of Environmental Science and Engineering, Shanghai Jiao Tong University, Shanghai 200240, China

3 Department Sociology and Rural Development, University of AJ\&K, Muzaffarabad, Pakistan

4 Department of Economics, Ghazi University Dera Ghazi Khan, Dera Ghazi Khan, Pakistan

5 School of Management, China Institute for studies in Energy Policy, Collaborative Innovation Centre for Energy Economics and Energy Policy, Xiamen University, Xiamen 361005, Fujian, China 
with a yearly demand of $12 \%$ per year and projects to reach 45 million people by 2040 , under a high case scenario (Government of Ghana 1994). Again, the country is set to achieve a $10 \%$ share of RES in its energy matrix by 2020.The wind is seen as the energy that can aid Ghana to achieve all these objectives. The country managed to achieve $0.2 \%$ in 2013 and $0.3 \%$ in 2015 (Government of Ghana, 2020). Ghana has not made much progress in the deployment of wind and other RES as a whole towards achieving that objective; it achieved $1 \%$ in 2018 of the $10 \%$ envisaged by 2020 (Bloomberg NEF 2020).

More so, Ghana was projected to achieve universal electrification by 2020 , which is behind schedule. Thus, the study would delve into factors that will determine the scaling up of wind energy in Ghana towards achieving this goal. The question that comes to mind is whether the policies enacted in the form of feed in tariffs (FiTs) and renewable purchase obligation(RPO) have failed to live up to the expectation of achieving the $10 \%$ target. The following studies have argued that FiTs and RPO are effective in scaling up wind energy and RES in general and should be pursued (Mohsin et al. 2018b, Panse and Kathuria 2016, and Mohsin et al. 2019b). In the wake of rising population growth, can the old pathway continue to meet the energy demand of the country, giving the projected high case scenario of the population of 45 million people in 2040 ? As Ghana has not met its universal electrification rate in 2020, scaling up wind energy would help in creating energy access and promoting socioeconomic development in the country. The electrification rate now stands at $87 \%$. Research by Rocco et al. (2020) confirmed that increasing electricity access could contribute significantly to economic growth.

Additionally, electricity access has a direct correlation to economic growth and promoting sustainable development and industrialization. Ghana's gross domestic product (GDP) has been on a growth trajectory and grew by over $6 \%$ last year in 2020 African Development Bank 2019). That means more energy is needed to fuel and sustain this growth. Hence, scaling up wind energy would be needed for this economic theory. The country's generation capacity is at 4310 megawatts (MW), without embedded generations from two major solar plants, at 2017 end, and the total generation with embedded solar plants is 14,069 gigawatt-hours (GWh) (Energy Commission of Ghana 2016). Obviously, this adequate generation comes from thermal sources, which is about $69.3 \%$. This is not sustainable and places a financial burden on the country and consumers as well. In 2017, Ghana imported 1.7 million barrels of crude diesel to power the thermal plants, for $\$ 63$ per barrel. This would increase to 3 million barrels in 2018 , with a per-barrel cost of $\$ 75$ and a levelized cost of operations to be around $\$ 225$ million (Energy Commission of Ghana 2016).

As a result, the aim of this paper is to find out the factors that would determine the scaling up of wind energy in Ghana.
Wind energy is a local, cheaper, and environmentally friendly fuel. Ghana has the potential in certain locations to generate utility-scale wind energy in Ghana. These locations are the eastern region, Greater Accra, Parts of Volta, and Asante regions. These areas have the minimum wind speed of $6.4 \mathrm{~m} / \mathrm{s}$ required for utility-scale wind farms. The factors have been grouped into policy, technical, socioeconomic, and geographic. Ghana has a technical potential for wind energy at $82.8 \mathrm{TWh}$ yearly and total final electricity consumption of 6.9 TWh a year (Mohsin et al. 2018a and Iqbal et al. 2019).There is a need to build grid infrastructure and modernize the existing ones to take on VRE. Ghana equally has a geographical potential of $8.5 \%$ of its total available area for the production of electricity. This makes a point that Ghana has a favorable landscape to deploy wind energy to achieve $100 \%$ electrification. Furthermore, with Ghana's population on a growth trajectory, with about $2 \%$ annual growth, it implies high urbanization and more income to spend on energy. But Ghana cannot scale up wind without leveraging a partnership with the private sector.

A favorable business environment would help in wind energy deployment in the country. After all, it is the private sector that would play a catalytic role in scaling up wind energy in Ghana, as have been done in South Africa with the REIPPP (SEWEA 2019), Kenya (Kazimierczuk 2019), and Morocco (Government of Morroco 2019), together with the African Development Bank (AfDB), a multilateral development institution, and other private developers.

A couple of studies have been done concerning the wind energy sector in Ghana. They include Adaramola et al. (2014) and Dzebre and Adaramola (2020). The study uses time series data, the vector auto regression (VAR) model to analyze the variable, using a multiple linear regression model to evaluate the impacts of these factors. All the variables are considered endogenous variables under this approach. Finally, to the best of our knowledge, this paper is the only one that uses the VAR model as well as the LCOE approach to analyze the wind energy market in Ghana. Asumadu-Sarkodie and Owusu (2016) used a similar approach in analyzing the key determinants of wind energy in Ghana, but did not include the LCOE approach. The results corroborate several studies and found all the variables to be significant in scaling up wind energy in Ghana. Our contribution also includes the provision of a wider perspective on discourse regarding scaling up wind energy in Ghana to meet our growing energy needs.

The rest of the paper is organized as follows: the "Literature review" section makes a deep dive to the literature on the wind industry in Ghana. The "Data and methodology" section describes research and methodology. The results of the analysis are described in the "Results and discussions" section. The "Conclusions and recommendations" section ends the paper with conclusions and recommendations. 


\section{Literature review}

This section provided a deep dive to the wind energy situation prevailing in the country, as well as the electricity generation dynamics of the country. It reviewed the literature related to the technical, theoretical, economic, and geographic wind energy potential of the country. It equally briefly reviewed that of Africa.

\section{Wind energy in Ghana}

Ghana started producing utility-scale renewable solar, precisely to the national grid in 2013. Before this, the nation relied on hydropower and thermal sources to meet the nation's energy needs. On the whole, renewable's total generation from the overall generation stands at $26 \mathrm{kWh}$ since 2016, which is about $0.1 \%$ of the total generation (Energy Commission of Ghana 2016). Ghana is yet to officially generate energy from wind to the national grid. The only wind farm under construction with about $225 \mathrm{MW}$ of nameplate capacity when completed is the Ayitepa, upwind farm, Accra. It has 75 turbines and heights up to $140 \mathrm{~m}$ (www.Ayitebafarm). This will add about $5 \%$ wind generation to the national grid. In this vein, wind energy has been viewed as renewable energy to help meet the energy needs of the country while saving the grid and maintaining macroeconomic stability. Ghana has an average wind speed of above $50 \mathrm{~m}$ to be $8 \mathrm{~m} / \mathrm{s}$ and could go as high as $9.9 \mathrm{~m} \mathrm{~m} / \mathrm{s}$ in certain locations, especially the coastal areas. Thus, with this potential, it is prudent to exploit it for the country's socioeconomic benefits and secure our future energy. Furthermore, the Volta River Authority (VRA) is partnering with two wind developers to build $150 \mathrm{MW}$ of wind power on four identified locations in Ghana based on wind resources potential (Government of Ghana, 2020).

The table below (Table 1) from Mentis et al. (2015) applied a scientific spatial analyst-based tool called the ArcGIS to get these figures that tell the technical and geographical wind potential of Ghana. ArcGIS is an online cloud-based mapping, analysis, and data storage that can be used to create, share, and manage maps and related geographic content. From the table, it is apparent that Ghana's wind energy technical potential can cost competitively provide about 13 -fold of its total final electricity consumption (TFC) per annum. This is because Ghana's total energy production for wind per year without grid restriction is $82.8 \mathrm{TWh}$ per year. And electricity for TFC is $6.9 \mathrm{TWh}$. Ghana does have enough land space available for the wind farm operation, $8.45 \%$ available. The capacity factor for wind in Ghana is not zero, but that which is greater than $20 \%$. The total wind power capacity is marginal for the entire country but very fair in some regions of Ghana: Greater Accra, Eastern, Asante, and some parts of the Volta region. These areas can produce utility-scale wind farms, with a wind of speed of $6 \mathrm{~m} / \mathrm{s}$.

\section{Model used for renewable module}

The model below shows the long-term realizable potential of RES-E from the International Energy Agency (IEA) (World Energy Model, 2019). It argues that the future deployment of RES-E depends on the assessment of the future potential of such a resource. Thus, it is adopted to assess and determine the future potential of wind energy deployment in Ghana. It first considers the theoretical potentials of Ghana in producing wind in Ghana. It looks at the geographical parameters that can be taken into account at the theoretical upper limit to produce energy from wind resources, given the scientific facts available. It discovered that Ghana has a huge technical and theoretical potential to produce energy from wind. Ghana has a total land area available for wind farm operation of $20,674 \mathrm{~km}^{2}$. The technical potential is the observations that require such necessary conditions such as the efficiency of conversion technologies and the available land areas to install wind farms (Mohsin et al., 2019a, b, c).

The technical potential is not a static condition; it is dynamic. The country has a technical potential of $82.8 \mathrm{TWh}$ of electricity production from no grid restriction (Sun et al. 2019).With continued research development and demonstrations, the technical potential can be increased and improved.

Table 1 The technical and geographical potential of wind energy in Ghana

\begin{tabular}{|c|c|c|c|c|c|}
\hline \multirow[t]{2}{*}{ Ghana } & \multirow[t]{2}{*}{ Total area PCS $\left(\mathrm{km}^{2}\right)$} & \multicolumn{2}{|l|}{ Grid restriction } & \multicolumn{2}{|l|}{ No grid restriction } \\
\hline & & Total available for wind farm $\left(\mathrm{km}^{2}\right)$ & $\%$ of the area availability & Total available for wind farm $\left(\mathrm{km}^{2}\right)$ & $\begin{array}{l}\% \text { of area } \\
\text { availability }\end{array}$ \\
\hline Geographical & 244,728 & 20,674 & $8.45 \%$ & 20,674 & $8.45 \%$ \\
\hline \multirow[t]{2}{*}{ Technical } & $\begin{array}{l}\text { Energy (TWh/year) } \\
\text { no grid restriction }\end{array}$ & Energy (TWh/year) grid restriction & $\begin{array}{l}\text { Energy (TWh/year) } \\
\text { CF }>20 \%\end{array}$ & Electricity TFC (TWh)/annum & \\
\hline & 82.8 & 82.8 & 0 & 6.9 & \\
\hline
\end{tabular}


Long-term realizable potential is an aspect of the technical potential of wind energy in Ghana that is achievable in the long run. To estimate it, the overall bottlenecks like technical feasibility, such as grid constraints, social acceptance to avoid NIMBY-ism, planning requirements and the value chain to ensure that local industry is established for the sector in creating local content for the economy. All these need to be addressed holistically for the industry to take off smoothly. The insert is a model for renewable energy deployment in Ghana, as explained above, wind in particular from the IEA (World Energy Model, 2019).

\section{Regions in Ghana with utility wind energy potential}

The under listed plots are for determining wind speed, power density, and rose frequencies in certain locations in Ghana. They are culled from the Global Wind Atlas system (https:// globalwindatlas.info). A plot of the average wind speed of Ghana is at $100 \mathrm{~m}$ wind speed @ height $100 \mathrm{~m} / \mathrm{s}$.

Figure 1 shows, from the figure above, a plot of the average wind speed of Ghana at height $100 \mathrm{~m}$, the vertical axis as the mean wind speed, and the percentage windiest of the area on the horizontal axis. This figure shows Ghana has the potential of generating utility-scale wind projects at height $100 \mathrm{~m}$ and wind frequency rose.

Figure 2 shows that wind frequency rose indicates the direction of the wind speed. It shows the flow and speed of the wind on the various cardinal points, north, south, east, and south. The three spokes around the southwest of Ghana show that $50 \%$ of the hourly wind direction comes from that direction that is, SW, S, and WSW. This indicates that wind hardly blows around the northeast of Ghana, and northwest of Ghana. They indicate that wind turbines could be installed there without obstacles to the speed of the wind blowing (Asbahi et al. 2019 and Sun et al. 2019).

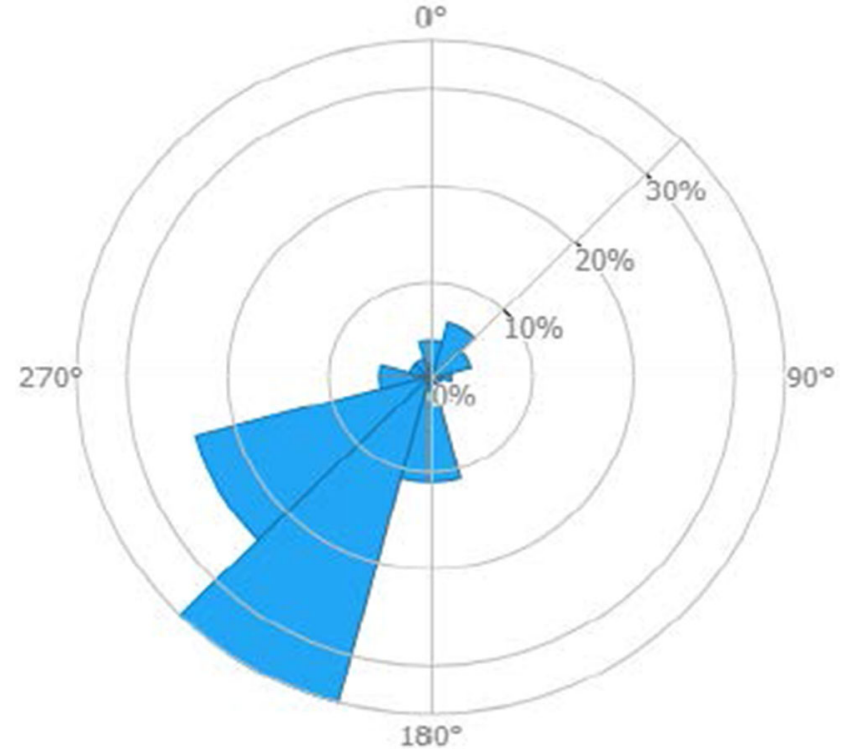

Fig. 2 Flow and speed of the wind on the various cardinal points (Global Wind Atlas)

Figure 3 shows that wind power density is used to evaluate the wind resource potential of a site. It explains the amount of wind energy available at a place that could be converted by wind turbines to produce electricity. It is measured in watts square meters. A wind power density in the range of 150 $200 \mathrm{~m}^{2}$ indicates a wind speed of 5.1-5 $6 \mathrm{~m} / \mathrm{s}$. Thus, by this mean of $150 \mathrm{w} / \mathrm{m}^{2}$, the wind speed is given in that range.

Figure 4, the above figure, shows the wind power density of the eastern region. It is indeed one of the regions in Ghana well-endowed with wind energy resources. Its wind power density is $232 \mathrm{~W} / \mathrm{m}^{2}$. This, therefore, suggests that the wind speed there is between 6.0 and $6.4 \mathrm{~m} / \mathrm{s}$. This has met the universal requirement for building a utility-scale wind farm. This is attributed to its mountainous area. The country should exploit this potential for its socioeconomic gains.
Fig. 1 Plot of the average wind speed of Ghana (Global Wind Atlas)

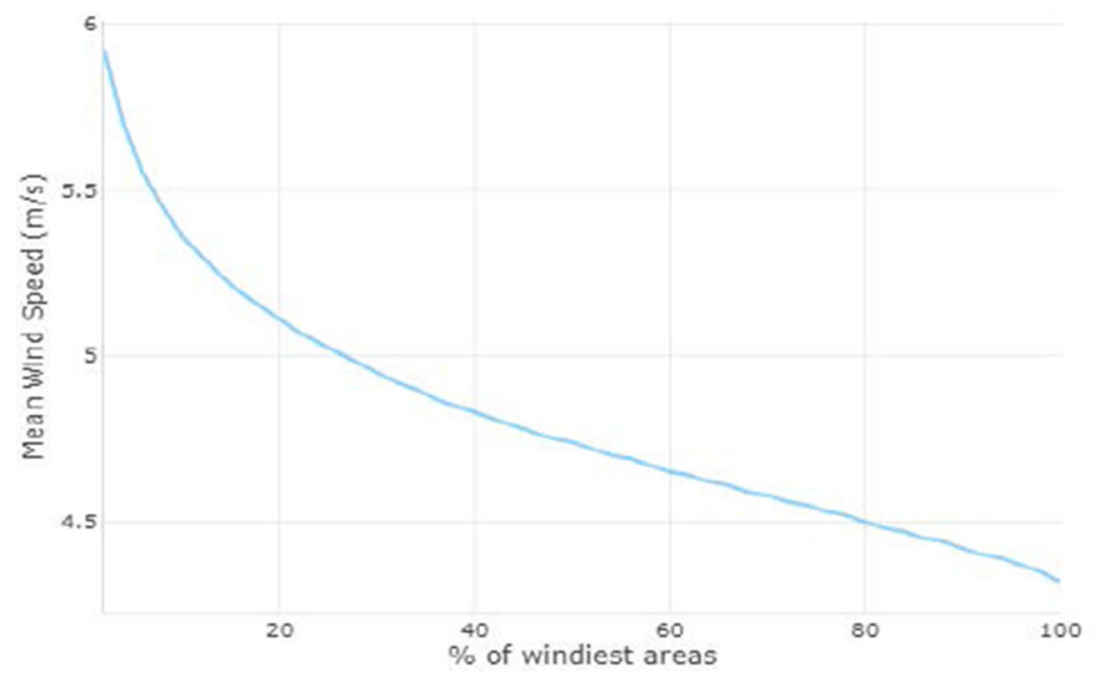


Fig. 3 Wind power density used to evaluate the wind resource potential of a site (Global Wind Atlas)

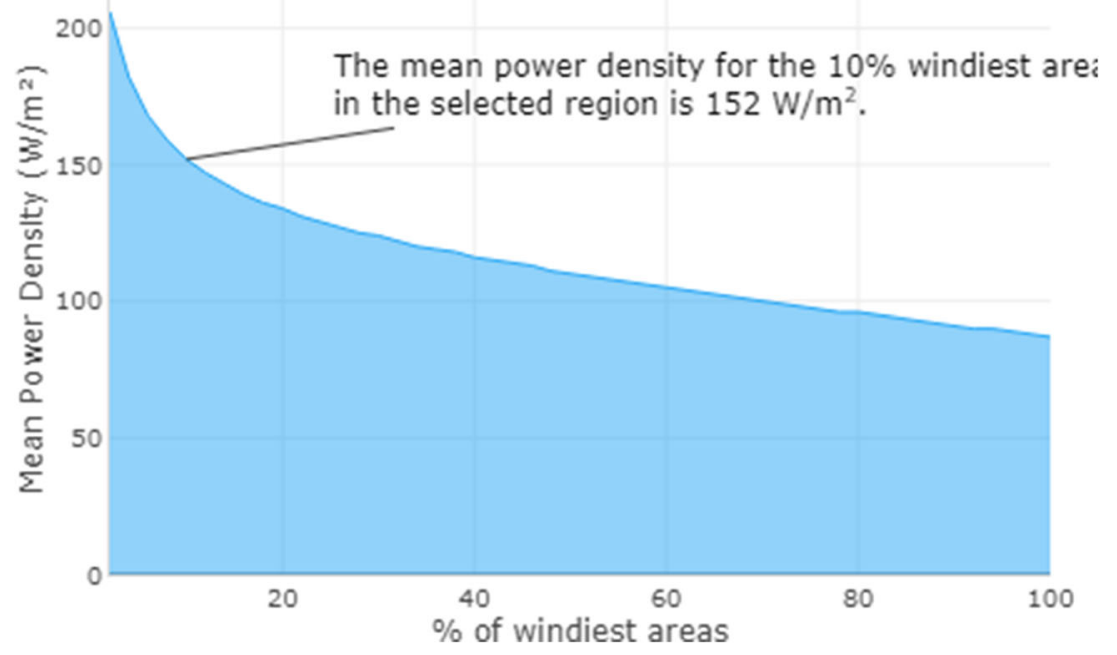

Figure 5 shows the vertical axis plots, the mean wind speed, and the horizontal axis in the windiest areas. It shows the eastern region has a wind speed of $6.0 \mathrm{~m} / \mathrm{s}$. It is a good area for the development of utility wind projects. As explained earlier, frequency rose explains the direction of the flow of wind speed. The directions of the flow of wind in the eastern region are in the S, SW, and WSW. The hourly wind speed is $105 \%$ that is a summation of the frequencies of the spokes. This shows that the wind does not blow from the northeast or the northwest. This indicates wind turbines could be installed in these areas in order to have a free flow of the wind. The mean wind speed, at the $10 \%$ windiest area, shows that Accra has a good wind speed of $6.03 \mathrm{~m} / \mathrm{s}$. It is one of the most windendowed wind resource sites in Ghana that is, where the Ayitepa wind farm is located, Ghana's only wind farm.

Figure 6 shows that the Greater Accra has a huge potential for utility-scale wind farm, with the mean speed density of the $10 \%$ windiest areas to be $232 \mathrm{~W} / \mathrm{m}^{2}$. Power density explains the wind resource availability of the area to produce electricity by wind turbines. This has a wind speed in the range of 6.0 $6.4 \mathrm{~m} / \mathrm{s}$. The figure from above shows the direction of the blow of wind in the Greater Accra region. The direction is mostly from southwest and west south, south. The direction of the flow of wind speed is $100 \%$.

Figure 7 shows that the Asante region of Ghana has the theoretical potential for utility wind farm operation, with the mean wind power density of $254 \mathrm{~W} / \mathrm{m}^{2}$, of $10 \%$ of its windiest area.

Figure 8 shows that the flowchart above shows the wind speed of the Asante region. Asante region is one of the regions with a fair wind speed at almost $7 \mathrm{~m} / \mathrm{s}$. This indicates that the region is endowed with the potential for utility-scale wind speed. The Asante region has a fair to good wind speed. The summation of the spokes of the wind speed is $100 \%$. And the direction of flow is around west, south, south, and southwest. These areas experience strong wind speed and suitable for wind farm siting. From the above, wind speed measurements from the Global Wind Atlas, three regions in Ghana, the Eastern, Asante, and Greater Accra region, met the wind speed requirements of above $6 \mathrm{~m} / \mathrm{s}$ for utility-scale wind power energy development. Because they have a speed limit of $6 \mathrm{~m} / \mathrm{s}$, of height $100 \mathrm{~m}$, the rest of the regions have the marginal potential for small scale wind energy development of $4 \mathrm{~m} / \mathrm{s}$. However, some areas in the Volta region, Anloga,
Fig. 4 Wind power density of the eastern region (Global Wind Atlas)

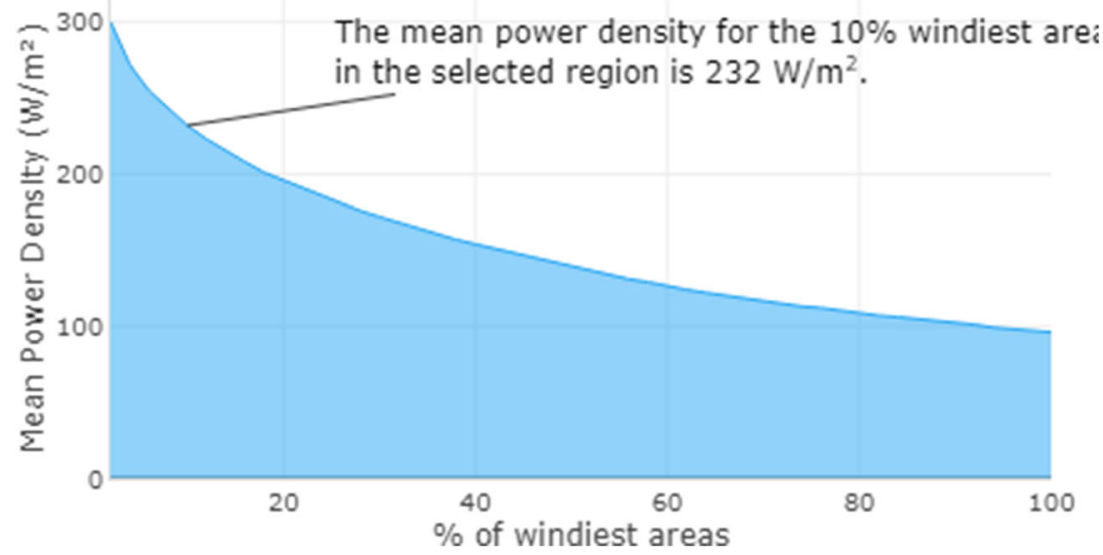


Fig. 5 Vertical axis plots, mean wind speed, and horizontal axis in the windiest areas. Source: Global Wind Atlas

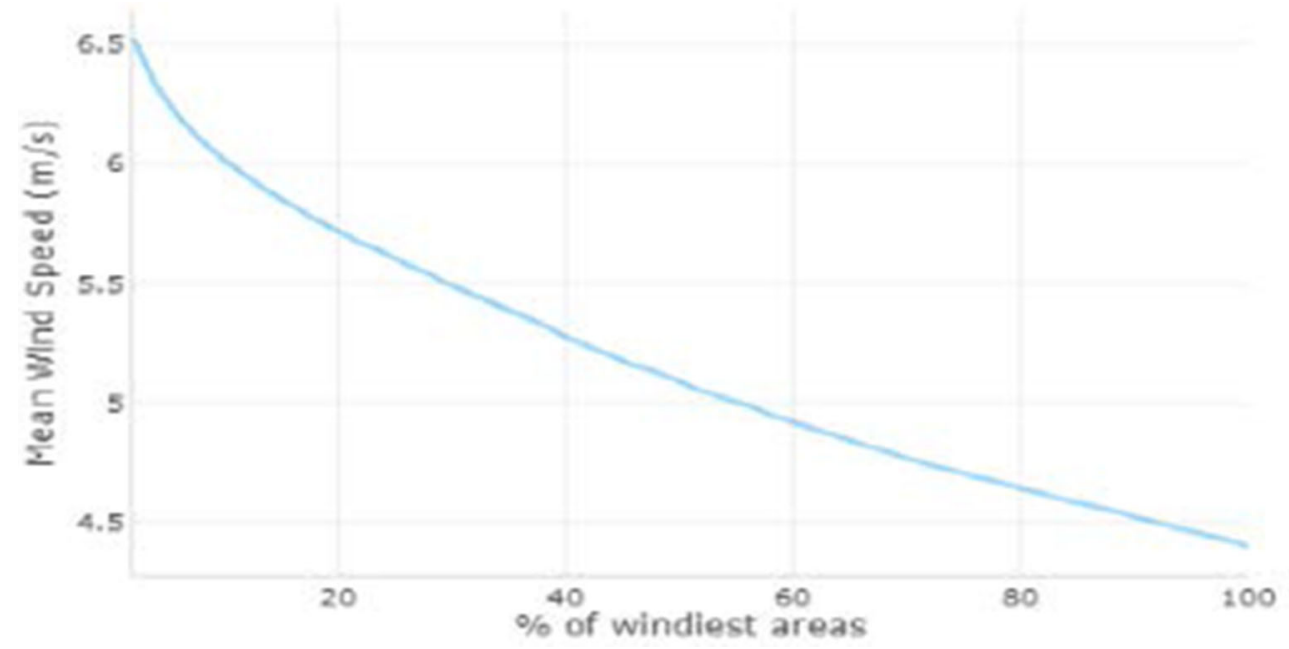

Keta, have a wind speed of $6.0 \mathrm{~m} / \mathrm{s}$ at $60 \mathrm{~m}$ (Government of Ghana, 2020).

\section{Ghana's electricity generation dynamics}

Ghana has about $84 \%$ of the electrification rate, second to South Africa, in sub-Saharan Africa. However, there is still a huge gap between rural and urban electrification (Bank et al. 2018). The country is expected to have universal electricity access by 2020 , which is behind schedule. The current electrification rate is about $87 \%$. Ghana's installed electricity generation capacity available for connection to the grid for the power supply was 4310 megawatts (MW). The installed generation capacity will increase to $4398.5 \mathrm{MW}$ if two major embedded solar generation plants are added at the subtransmission level. This is about a $16 \%$ increase in the installed capacity since 2016 (Energy Commission of
Ghana, 2016). The overall grid generation in the country, including embedded generations, stands at 14,069 gigawatthours (GWh), and this comprises $39.9 \%$ hydro, $59.9 \%$ thermal, and about $0.2 \%$ solar power. This represents an $8.4 \%$ increment over that of 2016. Ghana's total dependable capacity in 2017 was 3890 MW, far in surplus of over 1700 MW. With this generation capacity, Ghana is energy sufficient, all other things being equal. However, the concern is we generate so much from thermal sources that are quite expensive and not sustainable. Ghana equally aims to get universal electricity access and $10 \%$ electricity generation from hydro-nonrenewable sources by 2020 like other renewable energy areas (Iram et al. 2019; Sun et al. 2020a, b).

Ghana's per capita consumption of energy stands at $417 \mathrm{kWh}$ since 2017 due to an improvement in the electrification rate; it is, however, lower than $500 \mathrm{kWh}$ for middle income developing countries' level. The country in
Fig. 6 The direction of the blow of wind in the Greater Accra region (Global Wind Atlas)

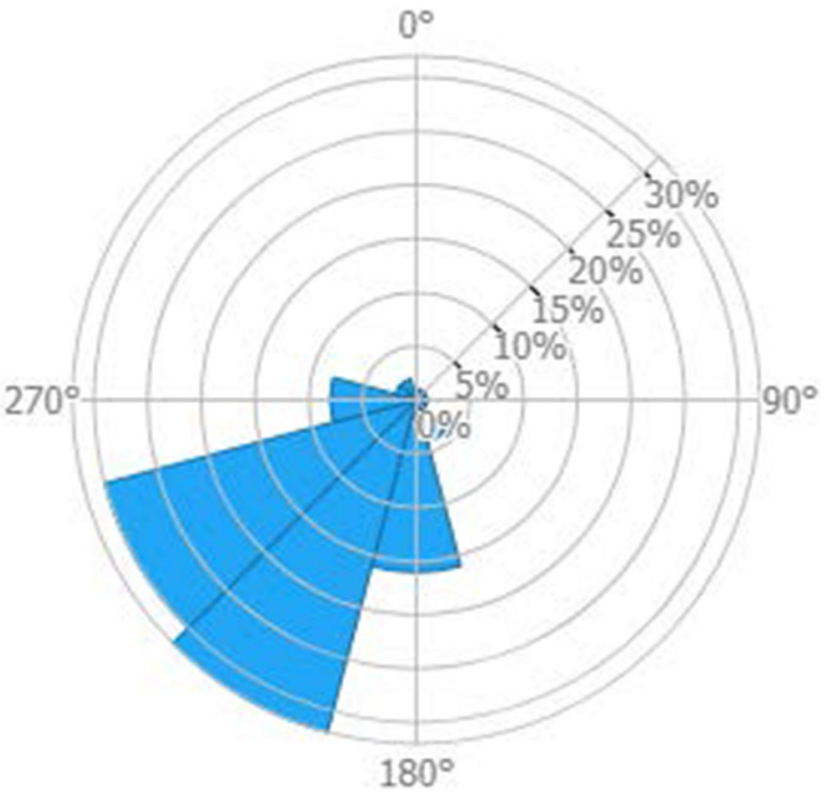


Fig. 7 The Asante region of Ghana which has the theoretical potential for utility wind farm operation. Source: Global Wind Atlas Maps

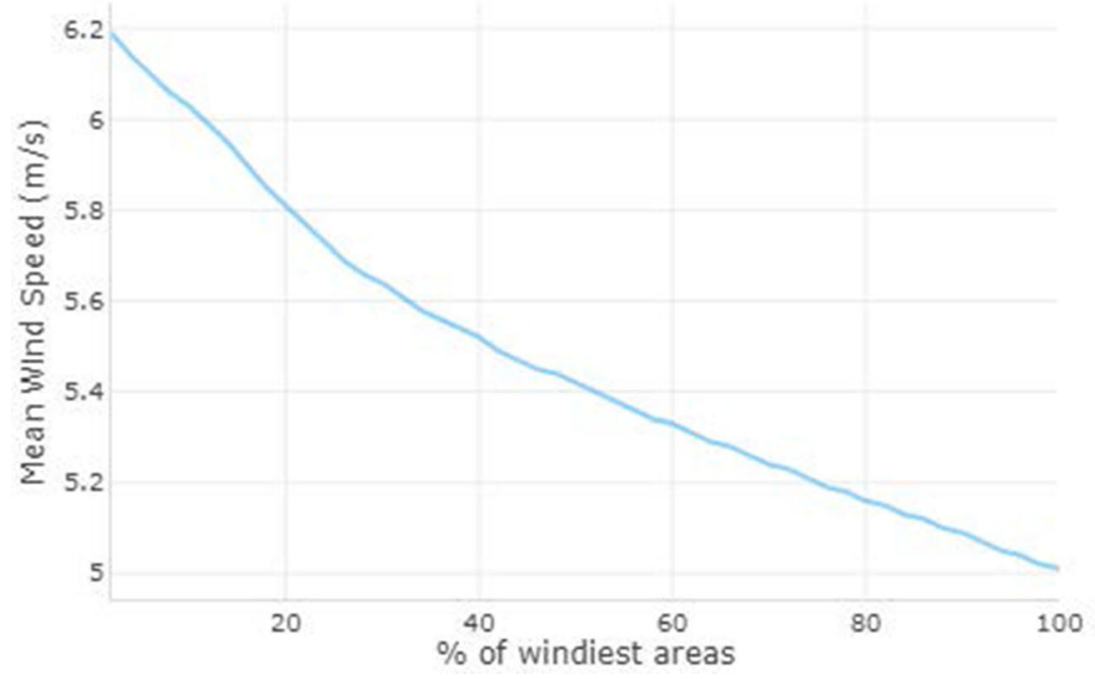

March 2018 reduced tariffs on all consumers, and despite this, the country still has one of the highest tariffs in middle income developing countries and Southeast Asia of an average of 15$19 \mathrm{kWh}$ cent. This stems from the country's bulk generation from thermal sources. South Africa has $8-10 \mathrm{~kW}$ per US cent, India has 8-9 kW per US cent, and Southeast Asia has 4$7 \mathrm{~kW}$ per US cent (Energy Commission of Ghana 2016). The total grid dependable capacity installed generated by thermal sources for 2018 was $4758.5 \mathrm{MW}$, and out of this, the dependable capacity was 4321.6 MW.

\section{Estimates of fuel cost of operating the plants in 2019}

From the table, Ghana will spend over $\$ 1$ billion in purchasing fuel for powering the thermal plants in 2019. This is about $\$ 86.64$ million per month on average. The cost is, however, higher for independent power plants in the range of US\$ 760.81 million, by per capita cost of US\$ 63.40. The VRA plants would spend US\$ 278.91 million, with per capita per plants of $\$ 23.24$ million in a month.

From the chart below (Table 2), thermal generation formed the biggest part of the total generation in 2018. On the other hand, the hydropower generation was $30.4 \%$ and solar was a meagre $0.03 \%$ in total. This does not give a good outlook for the electricity generation of the country. Most countries have reduced their reliance on fossil fuel generation. Chile is a quintessential global RES-E country, where renewables are making major inroads. Renewables have displaced mining as a top investment destination and, in 2016, became the world's second leading market for RES-E, trailing China, and first in the Americas. This was achieved by a relentless but gradual energy policy, attracting investments to the sector, since the dawn of the twenty-first century (Madariaga and Allain 2018). In 2019, Chile's wind energy-installed capacity increased by $18 \%$, with $526 \mathrm{MW}$ new installations (GWEC Report 2019). This was $11.4 \%$ lower than in 2016 (GWEC Report 2019). The cumulative of all the new installations and the old is now up to 650,758 MW in 2019 (WWEC Report, 2019). The biggest year for the global wind energy was 2019 with new installed capacity reaching a peak of $60.4 \mathrm{GW}$ by the end of 2019, onshore delivering 54.2 GW and offshore $6 \mathrm{GW}$ (GWEC Report, 2019). But the impact of COVID-19 on the industry is yet to be estimated as the lockdown has delayed projects.
Fig. 8 Wind speed of the Asante region. Source: Global Wind Atlas Maps

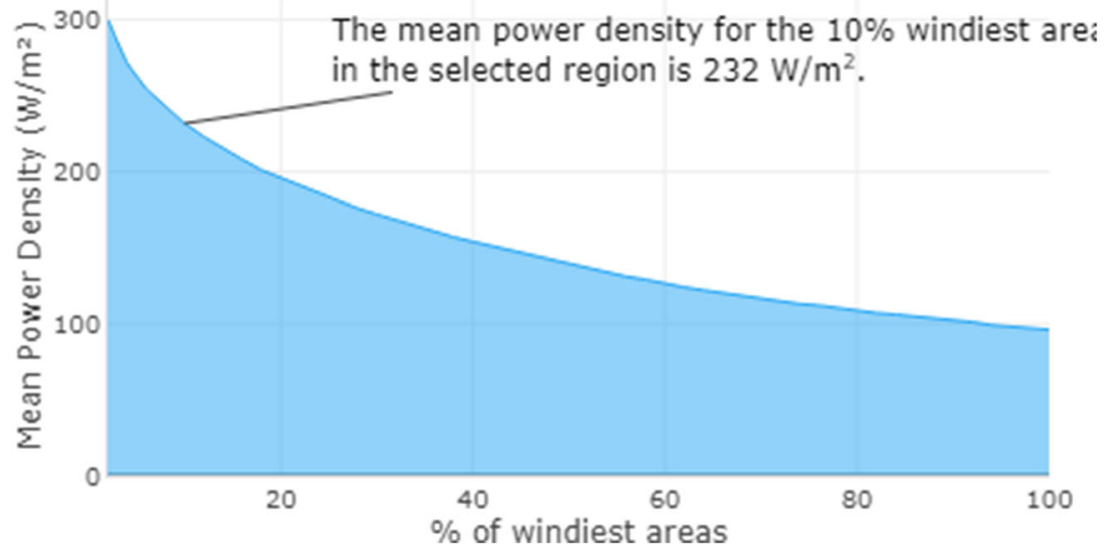


Table 2 Cost breakdown of cost for 2019

\begin{tabular}{ll}
\hline Fuel type & Cost (million dollars) \\
\hline VRA-GAS & 278.91 \\
Total VRA fuel cost & 278.91 \\
IPP-LCO & - \\
IPP-GAS & 314.18 \\
IPP-HFO & 445.93 \\
Total IPP fuel cost & 760.81 \\
Total VRA and IPP fuel cost & 1039.72 \\
\hline
\end{tabular}

Source: 2019 (Energy Commission of Ghana 2016) Table 3

\section{Africa's investment in wind energy space}

Wind farm energy projects in Africa started in the 1980s in North Africa. Since then, many African countries have embraced wind energy to promote energy access on the continent and bring economic development and growth. Electrification is the solution to providing energy access and encouraging energy economy and reducing energy poverty. Globally, about 840 million people still lack access to electricity, with a majority of them in sub-Saharan Africa. Thus, for Africa to bridge this gap, deploying renewables like the wind will come in handy and also meet the sustainable development goal seven by 2030. Africa, as of 2016, had four out of ten people who have access to electricity, while nine out of ten in the world have access to electricity. In the same year, 16 out of the 20 countries with the largest electricity access gap in the world are found in sub-Saharan Africa (Bureau 2018). Africa's share

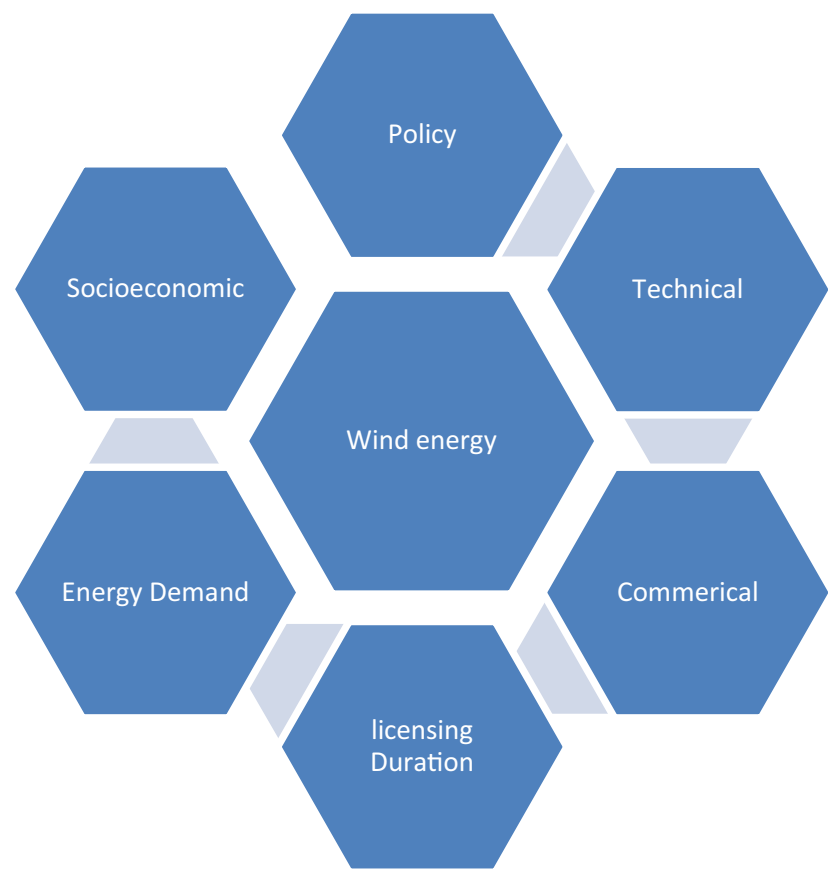

Fig. 9 Framework for wind energy development in Ghana of global wind energy-installed capacity is very negligible and stands at $0.08 \%$. Despite this, Africa has the potential of wind speed of $6.47 \mathrm{~m} / \mathrm{s}$ greater than the minimum $6 \mathrm{~m} / \mathrm{s}$ for building a utility-scale wind farm. In this vein, if sub-Saharan Africa wants to reduce this electricity gap and to increase electricity access by 2030 , it has to make renewable energy and wind energy deployment a top priority in the continent, not to continue as business as usual approach. If we continue as such, about 650 million people would not have access to electricity by 2030 .

The Tunisia Renewable Plan (TRP) aims to increase the mix of RES in its energy by $30 \%$ in 2030 (WWEC, 2019). In contrast, Algeria has 10.2 MW and 5 GW planned by 2030. Morocco has $1.2 \mathrm{GW}$ active capacity, $1.4 \mathrm{GW}$ under construction, and a total of 2640 MW planned by 2022 (WWEC, 2019). Egypt is another colossal for the wind industry in Africa with $1.4 \mathrm{GW}$ operational capacity and planned 1388 MW (WWEC, 2019). Kenya is blazing the trail in the East African region for wind, with $335 \mathrm{MW}$ installed capacity and another $350 \mathrm{MW}$ to come online by 2024 (GWEC 2019). Investment in the renewable energy sector in Africa is growing. Sub-Saharan Africa (SSA)'s investment in the renewable energy sector keeps fluctuating but increased by $70 \%$ in 2017-2018, with South Africa attracting 60\% of the investment, translating to $\$ 4$ billion in the clean energy sector (Bloomberg NEF, 2020). For sub-Saharan Africa to achieve universal electrification, about $\$ 27$ billion in investment is needed annually (OECD 2019). Thus, wind energy would help Africa in achieving this objective, giving the falling costs of wind.

\section{Regulatory framework for the promotion of renewable energy in Ghana}

The policy framework in Ghana that seeks to promote renewable energy use is the National Renewable Act 2011 (Ghana Renewable Energy ACT 2011 ACT 832). The act spells out strategies to manage and scale up the deployment of renewables in the country. This is to be done in a sustainable manner meeting the energy needs of heat, power, and other related matters. It further clearly stipulates the roles and responsibilities of various institutions, licensing processes, and requirements for electricity generation for instance, the feed tariffs that have been instituted and mandated to make the renewable energy business attractive to private investors, by guaranteeing them a market for energy generated from renewable sources. The act recommended the establishment of renewable energy fund for the promotion, development, and management and utilization of renewable energy. Money in the fund is to be spent directly in the provision of financial incentives such as feed tariffs, capital subsidies, and productionbased subsidies. The parliament of Ghana is to vote for the funding towards this purpose. 


\section{Data and methodology}

The framework (Fig. 9) below explains the drivers of wind energy deployment in Ghana. These factors will influence that the extent wind energy will be scaled up in Ghana. Time series data would be employed using the VAR model, in determining how the variables influence renewable energy development in Ghana and wind energy in particular.

\section{Data}

Four variables were used to analyze the data for Ghana. The policy variable was obtained from the International Energy Agency (IEA) and the Energy Commission of Ghana. The VAR was estimated using yearly data over the period of 2013-2019. The data were obtained from the World Bank's development indicators online and IEA. The population is measured in millions and wind capacity in megawatts (MW), and the economic growth rate was measured by using the per capita GDP growth rate (Constant 2000 USD). The VAR was chosen based on the stability of the coefficients of non-policy variables so that they could efficiently predict the dynamic behaviors of the variables in determining the scaling up wind energy deployment in Ghana. Before the data was analyzed, it was diagnosed for autocorrelation by using the Lagrange multiplier test, which came as no significant with a value of more than $5 \%$, thereby accepting the null hypothesis that there is no serial correlation in the VAR model. And hence, it could be used. Again, the model was checked for normality distribution test for the VAR, to determine for the distribution level, using the Jarque-Bera test. After conducting the normality test, most of them were normally distributed, which is satisfied for the VAR model. Thus, the VAR model passed the diagnostic test. The VAR allows for one lag for each variable in each situation, given the size of the sample, for each equation, which is accepted by the maximum likelihood ratio test. The lags give room for a succinctly dynamic structured VAR model, which does not over parameterize the VAR. More importantly, all series were stationary at I (I) before analyzing the data.

\section{Variables}

Wind capacity addition is the addition of installations in the country since 2013-2019; this would give a clearer view of the generation additions from renewables. The important factor for building a wind farm is having access to land. Without good land, no onshore wind farm can be set up. The Energy Commission under the Ghana Energy Development and Access Program (GEDAP), together with the Ministry of Petroleum, did a wind energy assessment in eight locations along the cost of Ghana to measure wind speed data with a reference point of $60 \mathrm{~m}$ above the ground level. This was done around 2011-2012. The average monthly wind speed ranged from 4.67 to about $6.01 \mathrm{~m} / \mathrm{s}$ (Energy Commission, 2014). Good and suitable land to building and operating a wind farm should be a flat land; there is a need to construct access road network, installation, and building of transmission equipment. The total land area of Ghana available for utility-scale wind farms is $20,674 \mathrm{~km}^{2}$ (Mentis et al. 2015):

a. Policy variables. Policies such as FiTs and renewable obligations (RPO) are very key in encouraging the rapid uptake of the wind resource in Ghana. Feed in tariffs essentially aim to ensure guaranteed prices for power produced from RES, but they are differentiated according to technology type, size of capacity, quality of the generation, location, and other variables that might impact in the generation of the electricity (Gass et al. 2013). The following works equally confirm the ability of FiTs and RPO to aid in effectively scaling up wind energy deployment (Ogura 2020, Zhao et al. 2020, Kilinc-ata 2016). The licensing regime prevailing in a country would determine how private companies can secure a license to operate and generate wind energy. If the process is rigorous and unnecessarily cumbersome, it will scare investors away to markets where the regime is simpler (farm.amp.html?0p19G=3248). A one-stop licensing regime would help in simplifying the process. The relationship between policies and wind capacity addition is anticipated to be a significant one, given the fact that the energy transition would be underpinned by sound policies.

b. Economic and social variables. As a result of a direct relationship between economic growth and energy consumption, Ghana, has a growing economy with a per annual $12 \%$ energy demand, will need more energy to meet this growing demand. A growing economy means a higher per capita income, due to people willing to pay higher for energy (Stigka et al. 2014). Obviously, higher income or GDP signifies two things: the ability to bear regulatory costs, in the forms of fiscal measures and market costs and having the wherewithal to spend on alternative energies (Marques et al. 2010).

c. Electrification rate. This explains the number of people that have access to electricity. Ghana has a current electrification rate of $87 \%$. The population is projected to reach 45 million by 2040 . This implies more energy demand. The wind is seen as a renewable source that can help in the universal electrification drive. Electricity consumption in any country is determined by energy demand and per capita consumption. Ghana's annual energy demand of $12 \%$ would drive consumption up the curve. Dong (2012) discovered that demand for wind energy levels in Germany grew as a result of an increase in energy demand. Thus, Ghana stands to gain if we consider meeting our growing energy demand from wind energy. A study 
by Shiu and Lam (2004) confirms the electricity consumption of the GDP of China to be cointegrated.

d. Technical variables. Due to the variable nature of wind energy or renewable energy, Ghana may not be willing to pursue it aggressively. Connecting it to the national grid is a matter of concern. However, we do have the back up in the form of dispatchable thermal gas and thermal plants. Thus, Ghana should pursue renewables aggressively. Ghana has a technical wind energy potential of $82.8 \mathrm{TWh} /$ yearly and $6.9 \mathrm{TWh}$ of total final electricity consumption yearly (Mentis et al. 2015). Given the appropriate grid infrastructure in place, wind energy deployment could be rapidly scaled up in Ghana. This is because the country has both the technical and economic potential to scale up wind energy deployment in selected regions.

\section{Vector auto regression for multivariate time series}

The VAR has been widely used to study the dynamic behavior of macroeconomic variables and financial variables, and for forecasting. It is a multi-equation system where all the variables are treated as endogenous variables. In its reduced form, the right hand side of the model has lagged values of all dependent variables in the model; there are no contemporaneous variables. It is a good model for policy analysis and structural inference. Hence, its application here is to determine how these variables would impact on wind capacity development, and the policies to be implemented towards achieving that aim.

$$
\begin{aligned}
& Y_{t}=\sum_{i=0}^{q} A Y_{t-}+\sum_{i=0}^{q} b i_{t-1}+v_{t}^{y} \\
& i_{t=}=\sum_{i=0}^{q} C^{\prime} Y_{t-1}+\sum_{i=1}^{q} d i_{t-1}+v_{t}^{i}
\end{aligned}
$$

From the equation, $Y_{t}$ is a $N x 1$ vector of non-policy variables, $i_{t}$ is the policy variable, $q$ is the number of lags in the $\mathrm{VAR}$, and $A, Z, B$, and $V$ stand for matrices or vectors. It is a system of the simultaneous equation where each variable is the past value of the current variable. The $v_{t}^{i}$ and the $v_{t}^{i}$ are the uncorrelated structural residual terms to the model. The vector of non-policy variables to the model is given by $\left[u_{t}, \pi_{t}, y_{t}, c_{t}\right]$ where $u_{t}$ stands for wind capacity, $\pi_{t}$ stands for population growth, $y_{t}$, represents the electrification rate, and $c_{t}$ represents the gross domestic product growth rate. A similar approach was applied by Sack (2000), using the VAR model to analyze the federal fund rate movement. This model was popularized by Chris Sims in his paper Macroeconomics and Reality (Christiano 2012). The policy variable $i$ comprises feed in
Table 3 Criteria and sub-criteria for wind energy

\begin{tabular}{lll}
\hline Criteria & Sub-criteria & Reference \\
\hline Social (SO) & Employment opportunities (SO2) & IRENA (2014) \\
& Public acceptance (SO1) & Guo et al. (2015) \\
& Local economic effect on development (SO3) & Enevoldsen and Valentine (2016) \\
& Population density (LO4) & Enevoldsen and Valentine (2016) \\
Location (LO) & Distance to residential areas (LO1) & Enevoldsen and Valentine (2016) \\
& Distance to main roads (LO2) & Enevoldsen et al. (2016) \\
& Distance to power lines transmission (on-grid) & (Renewable and Energy Agency \\
Environmental (EN) & Wildlife and habitat (EN2) & 2018) \\
& Carbon emissions saving (EN3) & Ramsi et al. (2020) \\
Geomorphological & Elevation (GR1) & Sepulveda et al. (2018) \\
(GR) & Slope (GR2) & Peter Bafoe and D.Sarpong (2018) \\
& Aspect (GR3) & Dzebre DEK, Adaraamola (2020) \\
Climate (CL) & Solar irradiation (CL1) & Dzebre DEK, Adaramola (2020) \\
& Relative humidity (CL2) & Michael et al. (2015) \\
& Annual air temperature (CL3) & Marques et al. (2010) \\
& Cost of land (EC1) & Md. Shariful Islam et al. (2013) \\
& & Stefano Grass et al. (2012); \\
& Infrastructural cost (EC2) & Valentina Dinica (2011) \\
& O/M cost (EC3) & International et al. (2018) \\
& & Voormolen, Junginger, and Sark \\
& & (2020) \\
& & Shiu and Lam (2004) and \\
& & \\
& &
\end{tabular}

Source: author's own creation 
tariffs and renewable purchase obligation (RPO), formulated and deployed to ensure the rapid uptake of wind energy capacity in Ghana. All these variables were selected based on their availability on previous works like Kilinc-ata (2016), Ogbe and Ogbe (2018), Thapar et al. (2018), Kang, et al. (2019), and Zhao et al. (2020). The reduced form of the equation is given below:

$$
\begin{aligned}
& X_{t}=\left\{\mu_{t}, \mu_{t-1, \cdots} \ldots, u_{t-8,} y_{t-1, \ldots .} y_{t-1 \ldots ., y_{t-8} \pi_{t}}\right. \\
& \left.\pi_{t-1}, \ldots \ldots, \pi_{t-8, c}, c_{t-1 \ldots \ldots,} C_{t-8, i_{t-1} \ldots \ldots, i_{t-8} t}\right\}
\end{aligned}
$$

The above equation shows the vector state that contains current and lagged values of non-policy variables and lagged values of Ghana's wind capacity addition.

It is the mathematical calculation of road distance between a wind farm and a national electricity grid. The variable of distribution and transmission distance is used for evaluating the risks existing in the transportation routes (Table 3 ). Thus, "transportation risk" is used as an indicator and is computed as follows: (Zhang et al. 2013)

$\mathrm{DTD}=\sum_{\mathrm{j}} \mathrm{RS}_{\mathrm{j}} \times\left(\frac{D_{\mathrm{j}}}{D_{\max }}\right)$

where DTD denotes the distribution and transmission distance from wind power project to national grids, $\mathrm{RS}_{\mathrm{j}}$ is the proportion of wind energy produced from wind power in Ghana, $D_{\mathrm{j}}$ is the distance of wind power projects to national grids, and $D_{\max }=D_{\max }\left[D_{\mathrm{j}}\right]$ is the longest distance where $D_{\mathrm{j}}=1$ if the distance between the wind farm power project and the national grids is less than $500 \mathrm{~km}, D_{\mathrm{j}}=2$ if the distance is between 1000 and $1500 \mathrm{~km}$, and $D_{\mathrm{j}}=3$ if the distance is greater $2000 \mathrm{~km}$. Now based on the above formula, each distance must be worked out separately to determine the least distance of transmission and distribution to the grid. So, if $D_{\mathrm{j}}=1$, the distance between the wind farm power project and the national grids is less $500 \mathrm{~km}$. $\mathrm{RS}_{\mathrm{j}}$ is the proportion of wind energy produced to the grid, $0.08 \mathrm{MW}$.

\begin{tabular}{|c|c|c|c|c|c|c|}
\hline & Coef. & Std. Err. & $\mathrm{Z}$ & $P>z$ & $95 \%$ conf. & Interval \\
\hline lnwindcap & 1.929 & 0.000 & $3.60 \mathrm{e}+14$ & 0.000 & 1.929 & 1.929 \\
\hline \multicolumn{7}{|l|}{ lnwindcap } \\
\hline $\begin{array}{l}\text { L1. } \\
\text { lnelectrrate }\end{array}$ & -2.530 & 0.000 & $-8.30 e+13$ & 0.000 & -2.530 & -2.530 \\
\hline $\begin{array}{l}\text { L1. } \\
\text { lngdpgrwth }\end{array}$ & 0.026 & 0.000 & $1.10 \mathrm{e}+13$ & 0.000 & 0.026 & 0.026 \\
\hline $\begin{array}{l}\text { L1. } \\
\text { lnpolicy }\end{array}$ & 0.439 & 0.000 & $8.00 \mathrm{e}+13$ & 0.000 & 0.439 & 0.439 \\
\hline $\begin{array}{l}\text { L1. } \\
\text { lngdpgrwth } \\
\text { lnwindcap }\end{array}$ & 0.122 & 0.000 & $1.50 \mathrm{e}+13$ & 0.000 & 0.122 & 0.122 \\
\hline $\begin{array}{l}\text { L1. } \\
\text { lnelectrrate }\end{array}$ & -4.261 & 0.000 & $-8.80 \mathrm{e}+13$ & 0.000 & -4.261 & -4.261 \\
\hline $\begin{array}{l}\text { L1. } \\
\text { lngdpgrwth }\end{array}$ & -0.064 & 0.000 & $-1.80 \mathrm{e}+13$ & 0.000 & -0.064 & -0.064 \\
\hline $\begin{array}{l}\text { L1. } \\
\text { lnpolicy }\end{array}$ & 1.997 & 0.000 & $2.30 \mathrm{e}+14$ & 0.000 & 1.997 & 1.997 \\
\hline $\begin{array}{l}\text { L1. } \\
\text { cons }\end{array}$ & 14.038 & 0.000 & $6.10 \mathrm{e}+13$ & 0.000 & 14.038 & 14.038 \\
\hline $\begin{array}{l}\text { Inpolicy } \\
\text { lnwindcap }\end{array}$ & -0.970 & 0.000 & $-1.80 \mathrm{e}+14$ & 0.000 & -0.970 & -0.970 \\
\hline $\begin{array}{l}\text { L1. } \\
\text { lnelectrrate }\end{array}$ & -3.972 & 0.000 & $-1.30 \mathrm{e}+14$ & 0.000 & -3.972 & -3.972 \\
\hline $\begin{array}{l}\text { L1. } \\
\text { lngdpgrwth }\end{array}$ & -0.625 & 0.000 & $-2.80 e+14$ & 0.000 & -0.625 & -0.625 \\
\hline $\begin{array}{l}\text { L1. } \\
\text { lnpolicy }\end{array}$ & 0.130 & 0.000 & $2.40 \mathrm{e}+13$ & 0.000 & 0.130 & 0.130 \\
\hline $\begin{array}{l}\text { L1. } \\
\text { cons }\end{array}$ & 24.320 & 0.000 & $1.70 \mathrm{e}+14$ & 0.000 & 24.320 & 24.320 \\
\hline
\end{tabular}

Table 4 Regression results

Author's calculation 
Then,

$\mathrm{DTD}=\sum_{\mathrm{j}} \mathrm{RS}_{\mathrm{j}} \times\left(\frac{D_{\mathrm{j}}}{D_{\max }}\right)$

$D_{\mathrm{j}} 500=0.08(1)=6250 \mathrm{~km}, D_{\mathrm{j}}=2, D_{\mathrm{j}}=2$ if the distance is between 1000 and $1500 \mathrm{~km}$, and $D_{\mathrm{j}} 1500 \mathrm{~km}=0.08(2)$, $1500=0.16$ divide through 0.16 by $\mathrm{MW}$ by $1500 \mathrm{~km}=$ $9375 \mathrm{~km}, D \mathrm{j}=3, D_{\mathrm{j}}=3$ if the distance is greater than $2000 \mathrm{~km}$, Then, $2000=0.08(3), 2000 \mathrm{~km}=0.24$, divide it by $0.24,8333.3 \mathrm{~km}$. Based on the results, one result with the least distance to the national grid is preferred in terms of constructing high-voltage direct current (HVDC) transmission lines. This is $D_{\mathrm{j}} 1$, which is $6250 \mathrm{~km}$. The shorter the distance to the population center, the least costly are the HVDC lines (Renewable and Agency 2018).

\section{Results and discussions}

\section{Analysis}

From the analysis above, the first lag of lnwindcap is significant to lnwindcap at [0.000] (Table 4) and has a direct correlation to lnwindcap. This suggests that as the first lag of lnwindcap increases, the lnwindcap increases as well. The significance level is perfectly significant at [0.00]. Similarly, Inelectrrate is significantly related to its first lag. However, it has a negative relationship with it. This, therefore, means that as the electrification rate increases, its first lag reduces at a rate of $[-2.530 \%]$. The overarching correlation is "Inelectrrate," which explains the number of people who have access to electricity is significant, signifying its predictive power in determining the scaling up of wind energy in Ghana. Thus, if Ghana wants to achieve its universal electrification rate, which was supposed to be achieved in 2020 (Kemausuor et al., 2017), wind energy should be given serious attention. Both distributed wind and utility-scale wind energy projects. Ghana's electrification rate stands at $87 \%$. All the variables are perfectly significant in determining the deployment of wind energy in Ghana. The difference lies in the direction of the correlation. Policy variables comprise FiTs and RPO. The policy variable is perfectly significant to scaling up wind energy in Ghana. The direction of the correlation is a positive one to its first lag. This implies that as policy variables increase, wind capacity in Ghana increases.

This suggests that favorable policies like FiTs and RPO are vitally important in increasing the deployment of wind energy in Ghana. Many studies have been done that support this assertion; they are Yang and Ge (2018), who contended FiTs are effective and reasonable to the deployment of distributed photovoltaic in China and should be amended regularly to reflect market dynamics. In addition, Barbosa et al. (2018) asserted that FiTs with a minimum guaranteed price would attract investment even if revenue is less than the actual investment when a risk-free investment is being offered. Zhao et al. (2020) in their paper, delving into the effectiveness of wind power policy in China, found price policy and two nonprice policy to have significant effects on the deployment of wind energy in China, of which price is vitally important to the deployment of wind in China. The likes of Kilinc-ata (2016), Dong (2012), Marques et al. (2010), Shrimali et al. (2015), and several notable authors concurred to this claim that FiTs are very important in helping scale up RES-E and wind energy in particular. Yin and Powers (2010) found renewable purchase standards to influence the deployment of RES in some states, in the USA, positively. Again, the first lag of lngdp influences significantly lngdp, and has a positive correlation with the estimates of the coefficient of lngdp, at [0.026\%]. Marques et al. (2010) and Aguirre and Ibikunle (2014) attested to this result from their works by arriving at a conclusion of the direct relationship between electrification rate and GDP growth.

Not only this but also, from the ensuing equation, lnwindcap influences lngdpgrwth, with a significant correlation coefficient of [0.122\%]. A study by Rocco et al. (2020) said increasing electricity access can significantly contribute to the economic growth of the Tanzanian economy. The critical importance of having universal access to electricity cannot be over emphasized; it creates an energy economy and improves health delivery as well as other socioeconomic benefits (Almeshqab and Selim 2019).On the other VAR variables, lnelectrrate has a negative relationship with its first lag. When lnelectrrate increases, its first lag reduces by [4.261]. lngdp has a significant inverse relationship with its first lag of $[-0.06 \% 4]$ coefficient. Inpolicy is statistically significant to its first lag with [1.997\%] coefficient. In the final equation, lnwindcap is statistically significant but with an inverse relationship to its first lag. Inelectrrate and lngdp both have a significant inverse relationship with their first lag values. Meaning when the current variable increases, the lag variable reduces. However, Inpolicy has a positive relationship with its first lag from this equation. This implies as Inpolicy increases, its first lag increases. These results are very key in policy inferences regarding wind capacity deployment in Ghana. They provide the direction and magnitude of these variables in their coefficients.

\section{The impulse response function of the model}

Impulse response functions (IRFs) are used in studying the interaction among variables in a VAR model. They exhibit the responses of the variables to shocks hitting the system. From the analysis done, it explained the dynamic behaviors of these variables when shocks come and their interaction affects on wind capacity addition in Ghana. In the wake of 

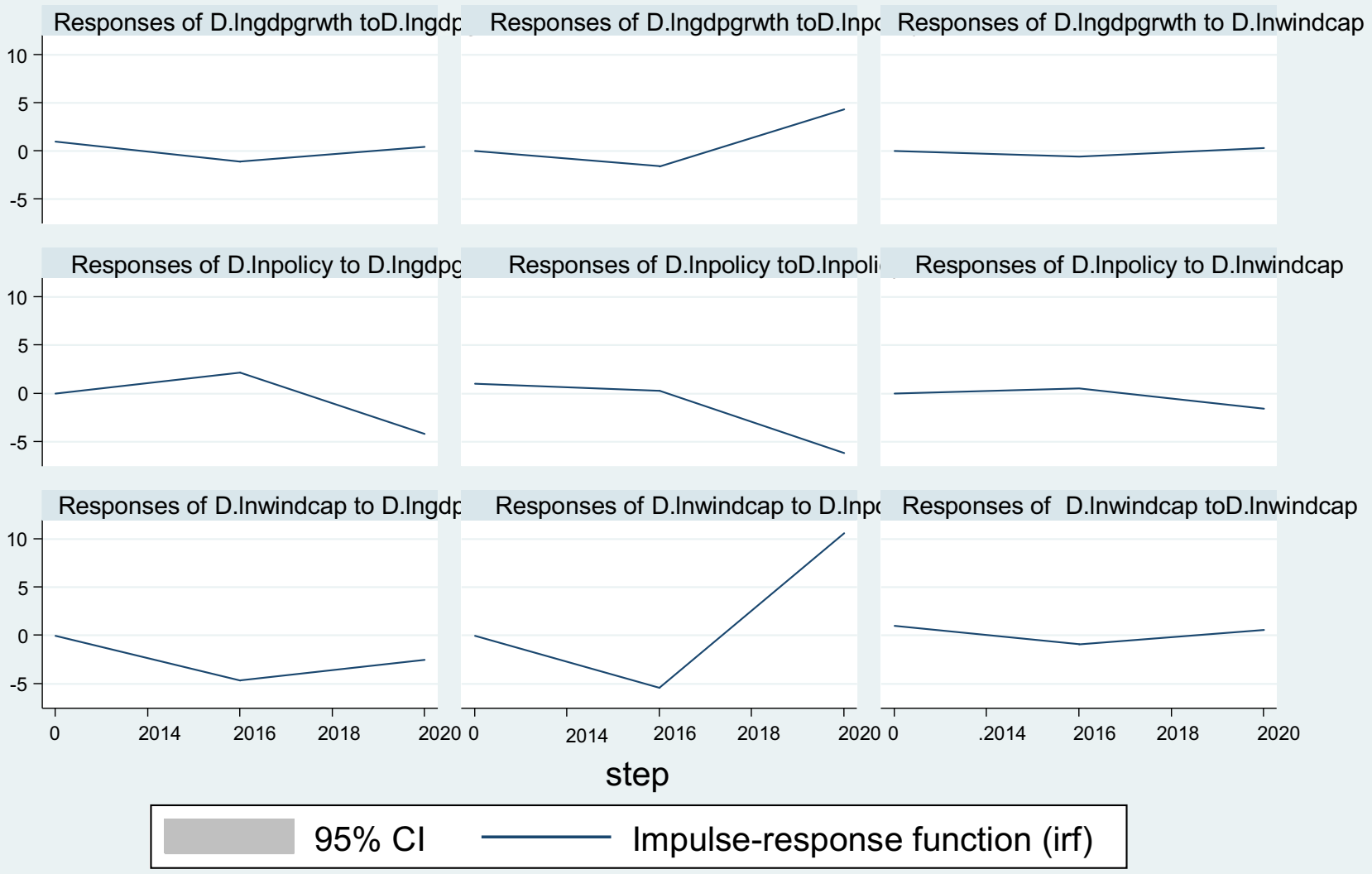

Fig. 10 Impulse response function

the corona pandemic, which is a negative shock, how will the variables respond to this shock from the pandemic regarding wind projects in Ghana? From equation one, $v_{t}^{z}$ and $\nu_{t}^{i}$ are structural disturbance terms of the model, which are a linear transformation of the economically fundamental shock, $\varepsilon_{t}$ shocks are of independent origins that are uncorrelated to each other. This is shown in the equation below:

$U_{t}=C_{\varepsilon t} \quad C C^{\prime}=V$

$B_{i}$ and $V$ have been known econometrically, and to estimate them, a series of regressions have been run and their variances and covariance in the regression disturbances were computed. This is shown below from the graphs from the stata output.

Figure 10 shows that the IRF graph above shows the impulse response functions at their $95 \%$ confidence level. A negative shock in the form of the corona pandemic hits the system and brings some responses from the variables. It is clear from the IRFs that the first difference of lngdp responded to the interaction rendered by the shock to itself by starting off from zero and moved downward a bit and continued climbing upward from 2016. Again, the first difference between lngdpgrwth and lnpolicy responded to the shock by starting from zero in the short run and continued to a growth pattern in 2020. The first difference of lnwindcap and lngdp reacted to the negative shock by taking on a high pedestal and went higher in 2016 and nosedived the same year towards negative in 2018. The response of the first difference of lnpolicy and lwindcap started off from zero in the short run and moved steadily towards negative close to 2016. On the other hand, the response of the first difference of Inpolicy to lnwindcap is quite similar to the previous trend. It started off from zero and then increased upwards in 2015. It went downwards in 2016. The response of the first differences of lnwindcap, Ingdp, lnwindcap, and lnpolicy follows a similar pattern after taking off from zero and moving towards negative and picking to a growth pathway in 2018 onwards. This is plausible as the interaction of these variables would lead to the addition of wind capacity in the long run in the country. On the whole, the intuition is that the shocks to the system have a positive impact on the long run, as the variables take on a growth trajectory, regardless of the negative directions the headwinds produced in some situations. 


\section{Levelized cost of generating systems operating in Ghana}

Levelized cost of electricity (LCOE) explains the cost per unit produced by a plant of its entire lifespan. It is used to compare and choose the best technologies available that are efficient and effective in producing electricity. Generally speaking, it comes in handy in making economic decisions regarding projects and the utility rates being offered in electricity project development. It is, however, worthy of note that one negative side of using the LCOE is it does not address likely social and environmental externalities and the long-term consequences of conventional generational technologies that are hard to capture in the measurement, such as nuclear waste disposal and environmental impacts (' $\mathrm{L}$ a $\mathrm{z}$ an $\mathrm{r}$ d's Levelised Cost of Energy Analysis: 2018). Below is a levelized cost calculation for the various energy generation sources in Ghana. A calculation of the levelized costs of energy is given below.

$$
\sum_{t=1}^{\sum_{t=1} n} \frac{I_{t}+\mathrm{M}_{t}+F_{t}}{\frac{\mathrm{E}_{t}}{(1+r)^{t}}}
$$

where $I_{t}$ is the investment opportunities in year $t$ (including financing), $M_{t}$ is the operations and maintenance in a year, $F_{t}$ is the fuel expenditure in a year, $E$ is the electricity generation in a year, and $r$ is the discount rate. The interest rate is prevailing in Ghana; $n$ is the life of the system. This explains the lifespan of the operating system. The LCOE calculator ('Calculator_Levelized_Cost_of_Electricity_And_FIT_Comparison_V1',) was in euros; therefore, the exchange rate of the cedis to the EURO is $\phi 1$ is equivalent to 5.8417 euros. From the calculation, the WACC is $12 \%$ for the fossil thermal plants. And $7 \%$ for the renewable, the $\mathrm{CO} 2-\operatorname{cost}(\mathrm{Gh} \phi / \operatorname{cost})$ was 11.2, while the $\mathrm{CO} 2$ emission factor ( $\mathrm{tCO} 2 / \mathrm{MWhtherm})$ varied depending on the plant. These factors are not computed in renewables LCOE, emission factor, efficiency level, CO2-cost (EUR/tCO2), and fuel cost. For the cost of the initial investment in generating plants, see the International Renewable Energy Agency (Renewable and Agency 2018). From the table, the levelized cost of energy for thermal is quite higher than the renewable sources. KTPP has an LCOE of Gh $₫ 218.19 \mathrm{kWh}$, and Karpowership was Gh $\varnothing$ $96.67 \mathrm{kWh}$. The highest LCOE for the thermal plants is the CENIT power plant of Gh $\$ 351.44 \mathrm{kWh}$. TAPCO's LCOE is Gh $₫ 227.60 \mathrm{kWh}$. On the other hand, Sunon Asogli Power (Ghana) Ltd. (SAPP) I \&II have an LCOE of Ghф170.23 per kWh. TICO has another lower LCOE of Gh $₫ 109.23$ per kWh. Ameri has an LCOE of Ghф163.40 per $\mathrm{kWh}$. On the other hand, obviously, renewables have the lowest LCOE. Akosombo has an LCOE of Ghф $4.08 \mathrm{kWh}$. BXC solar has Ghф22.07 kWh. VRA solar has $\mathrm{Gh} \notin 481.81 \mathrm{kWh}$. The variables, policy, GDP, electrification, and population growth were actually perfectly significant, which indicated a very strong correlation. Their first difference lags were equally significant, but with varied directions of magnitude. The impulse response functions (IRFs) indicated long-run interaction effects on each other, after the shocks and in scaling up wind energy in Ghana. The shocks to the system mostly produced shortrun relationships, but the overarching one was a positive outlook in the long run in scaling up wind energy in Ghana.

\section{Discussion}

This is stipulated in the National Renewable Energy Act as the main reason for ensuring that energy generated from renewable sources is given a guaranteed market. Renewable feed tariff schemes consist of feed in tariff rates. This gives an assured fixed rate of electricity from renewable sources for 10 years, subject to review every 2 years. The Public Utility Regulatory Commission shall determine the rates for the feed in tariffs. Companies that breach the terms spelled out shall be liable to conviction, Renewable purchase obligation, an electricity distribution company or a bulk electricity buyer shall buy a specified percentage of renewable electricity from renewable sources. The Public Utility Company shall, in consultation with the Energy Commission, determine the amount of electricity to be purchased by bulk electricity distribution companies, a connection to distribution and connection systems. An electricity distribution or transmission system operator shall connect a generator of electricity from renewable sources within the jurisdiction of the transmission and distribution system operator and the generator. The costs involved in connecting installations to the metering point of the grid must be borne by the generator of the electricity from the renewables. And the system operator must upgrade the system to take electricity from the generator at his cost. Failure to make it possible for electricity generators from a renewable source to hook to the national grid is crime liable for punishment. All these are aimed at promoting the use of renewables in the country as well as energy wheeling and banking, that is, bulk consumers can generate wheel power from wind farms to the facility to act as a storage house for them and pay the facility for storage and take it as when they need it (Thapar et al. 2018). These have led to an exponential growth of the Indian wind sector, delivering about $7 \mathrm{GW}$ more to the existing capacity of wind in 2003-2010 (Thapar et al. 2018).

The figure above shows the main actors in the renewable energy space in Ghana. The Ministry of Power oversees the renewable energy sector. It was empowered by the Renewable Energy Act 823 to promote renewable energy in Ghana. The Ministry of Environment, Science, Technology, and Innovation see the promotion of science and technology in 
the country. The technical regulator and advisor to the government on RES-E matter is the Energy Commission. Issues regarding licenses and permits are handled by the Energy Commission. The Public Utility Regulatory Commission (PURC) has diversified the mandate of setting tariffs. It determines the rates for the purchase of electricity from conventional and non-conventional sources. The Environmental Protection Agency (EPA) helps in protecting and promoting environmental policies. Both the Bui Power and the Volta River Authority have the sole responsibility of power generation in the country. The Ghana Grid Company Ltd. (Gridco) is responsible for power transmission in the country. Electricity Company of Ghana (ECG) is equally responsible for distribution in the southern sector of Ghana, while the Northern Electricity Company (Nedco) is responsible for power distribution in the northern part of Ghana. The Enclave Power Company is the only private company responsible for power transmission in the free enclave area of Tema, Ghana. Finally, the Ghana Standards Authority is responsible for complying with standards, and certification for equipment importation.

Ghana's renewable master plan is a framework that is investor-friendly and aims to encourage the development and promotion of the country's renewable energy sector for its socioeconomic development and mitigates the impacts of climate change, helping the nation achieve SDG 7. It seeks to encourage private sector participation in increasing the mass deployment of renewable energy in Ghana. The plan, when implemented, would achieve the following objectives up to 2030: to increase the use of RES in the national energy mix from 42.5 to $1363.63 \mathrm{MW}$, with 2015 as the base year to 2030; to connect about 1000 off-grid communities with the behind-the-meter renewable solutions or through distributed generations; and to encourage and stimulates local content participation in the renewable energy sector.

\section{Conclusions and recommendations}

This study analyzed the key determinants of developing wind energy in Ghana using a VAR model to measure variables such as wind capacity, policy variables in the form of feed in tariffs, RPO, and social, economic variables like GDP, population growth rate, electrification rate, and its related variables. The VAR model gives a way to study the dynamic behavior of these variables to scaling up wind energy in Ghana, making inferences from the relationships they provide through the OLS regression and through the impulse response functions (IRFs). The entire variables were perfectly significant in predicting the relationships but had varied correlations to each other. It is certain that for Ghana to develop its renewable energy sector and achieve a $10 \%$ target of generating electricity from renewable sources by 2030 , and also to achieve universal access to electricity, it has to give these key determinants a careful consideration to see how they can help in the rapid deployment of renewables and achieve that objective and even beyond. The transition to this pathway would be underpinned by policy and regulation; it must be said, if we do not do this, we are in a technology lock-in-state, regarding energy generation in the country.

The policy variable in the form of FiTs is generally used to ensure investors get a guaranteed price for electricity generated from renewable sources. It is a financial derisking instrument that compensates for risks in the renewable sector. This outcome was in line with most works regarding the vital importance of FiTs in promoting the rapid uptake of renewable energy deployment, especially wind by Shrimali, Lynes, and Indvik (2015), Kilinc-ata (2016), and Dong (2012). Since Germany first introduced this model in the 1990s, it has gained popularity across the globe, promoting the scaling up of renewable energy capacity in Germany and countries that benchmarked from the EEG. However, Germany has since replaced it with auction (Morris and Pehnt n.d.). The electrification rate variable was significant, and this was expected; as wind energy deployment increases either through utility-scale or distributed wind, it would help Ghana meet its universal electrification, which is behind schedule. Eberhard and Dyson (2020) found a causal relationship between electricity use and GDP growth to have a unit or bidirectional effects. Greater access to electricity can significantly change the socioeconomic life of rural dwellers, like improved education delivery and health delivery (Almeshqab and Selim 2019).

Ghana has a growing population; this means more demand for energy. The country has a yearly energy demand of $12 \%$ and a population growth rate of over $2 \%$. The country is projected to have over 45 million people under a high case scenario in 2040. This will need sufficient energy, and so investing in wind energy will help meet this growing demand.

On the part of the LCOE of the various generation technologies available in Ghana, KTTP has Gh $\phi 218.19 \mathrm{kWh}$ as the LCOE value. From the analysis, all the thermal generation technologies have a higher LCOE. The highest being CENIT power, with Gh $\$ 351.44$ LCOE. The reason is obvious; thermal generation is expensive than non-conventional sources. On the other hand, all the renewables have a lower LCOE, with Akosombo having the lowest LOCE of Gh $\phi$ $4 \mathrm{kWh}$. There is a striking value LCOE from VRA solar with the highest LCOE of Gh $₫ 481.81 \mathrm{kWh}$. This was not expected from the analysis. Hydropower dams have the longest lifespan of 100 years. One hundred years was used as the lifespan for Akosombo, and 20 years was used to the life span of thermal plants. Therefore, it stands to reason that Ghana should pursue renewable energy, wind for that matter, which has continued falling costs (International et al. 2018), as well as environmentally friendly cost. It would also bring about macroeconomic stability to the country. 
Following the findings, the under listed recommendations are made:

1. For wind energy to be scaled up in Ghana, it would be underpinned by the policy. Policy and regulatory obstacles must be addressed. Germany is the pioneer of FiTs which has switched to auctioning (Morris and Pehnt 2016). According to Irena (2017), in 2017-2018, there are about 55 countries contracting RE-based electricity using auctions; by the end of 2018, the number had increased to 106. That is, these countries have used auction for any of the RES. Auctioning and FiTs are both used to incentivize the uptake of renewables. Ghana is using auction in the fossil fuel sector, which has led to overcapacity, which leads to a curtailment in the power sector.

2. Ghana should strive to set an ambitious target for generating electricity from wind. The $10 \%$ target of 2030 is not ambitious enough. The continued fall in the costs, coupled with technological advancements, makes it a necessary condition and economic justification to pursue wind. Onshore wind and solar are due to offer less cost competitive electricity beyond 2020, cheaper than any low cost fossil fuel plant, without financial assistance (Irena, 2018).

3. Furthermore, Ghana should simplify the process of PPAs to a simple 2 page document. This is because many small scale investors do not have the financial wherewithal to hire lawyers to write voluminous PPAs for power contracts. Germany has simplified the process of PPAs to a simple written document. This has helped in scaling renewables in Germany (Morris and Pehnt 2016).

4. Ghana needs a national research center for wind energy and other RES. Research Development and Demonstration (RDD\&D) is very key to the development of the renewables' industry.

5. The challenge with Ghana is how to seamlessly integrate systems and institutions. The issue of building transmission networks is a major concern; it is capital intensive. This paper (Transmission Issues Associated with Renewable Energy in Texas 2005) confirms our assertion. The country has to reconfigure the power system to hook variable renewable energy (VRE) to the national grid. All these will depend on long-term plans and the right investments. There is a need for a new governance framework for the electricity sector in Ghana, in the face of rising renewable energy penetration across the globe. This has to be all-encompassing reforms including political, technical, institutional, and regulatory (Mitchell 2019).

6. Finally, the eastern region, Asante, and the Greater Accra regions have the highest wind speed for utility-scale wind farm development. Ghana can harness the wind energy potential there for the socioeconomic benefits of the country and accelerate the universal electricity access in the country.

\section{References}

Adaramola MS, Agelin-Chaab M, Paul SS (2014) Assessment of wind power generation along the coast of Ghana. Energy Convers Manag 77:61-69. https://doi.org/10.1016/j.enconman.2013.09.005

Aguirre M, Ibikunle G (2014) Determinants of renewable energy growth: a global sample analysis. Energy Policy 69:374-384

Almeshqab F, Selim T (2019) Lessons learned from rural electrification initiatives in developing countries: insights for technical, social, financial and public policy aspects. 102:35-53. https://doi.org/10. 1016/j.rser.2018.11.035

Al Asbahi AAMH, Gang FZ, Iqbal W et al (2019) Novel approach of Principal Component Analysis method to assess the national energy performance via Energy Trilemma Index. Energy Rep 5:704-713. https://doi.org/10.1016/j.egyr.2019.06.009

Asumadu-Sarkodie S, Owusu PA (2016) Multivariate co-integration analysis of the Kaya factors in Ghana. Environ Sci Pollut Res 23: 9934-9943. https://doi.org/10.1007/s11356-016-6245-9

Bank TW, Stage A, Prepared D, No R (2018) Combined project information documents/integrated safeguards datasheet (PID/ISDS). 113

Bank African Development (2019) African Economic Outlook 2019: macroeconomic performance and prospects jobs, growth, and firm dynamism integration; integration for Africa's economic prosperity

Barbosa L, Ferrão P, Rodrigues A, Sardinha A (2018) Feed-in tariffs with minimum price guarantees and regulatory uncertainty. Energy Econ 72:517-541. https://doi.org/10.1016/j.eneco.2018.04.028

Bloomberg (2020) Sub-Saharan Africa Market Outlook 2020

Bureau UR (2018) Transforming lives through renewable energy access in Africa UNDP's Contributions UNDP Regional Bureau for Africa (RBA) 1

Christiano LJ (2012) Christopher A. Sims and vector. 114:1082-1104. https://doi.org/10.1111/j.1467-9442.2012.01737.x

Dong CG (2012) Feed-in tariff vs. renewable portfolio standard: an empirical test of their relative effectiveness in promoting wind capacity development. Energy Policy 42:476-485. https://doi.org/10.1016/j. enpol.2011.12.014

Dzebre DEK, Adaramola MS (2020) A preliminary sensitivity study of Planetary Boundary Layer parameterisation schemes in the weather research and forecasting model to surface winds in coastal Ghana. Renew Energy 146:66-86. https://doi.org/10.1016/j.renene.2019. 06.133

Eberhard A, Dyson G (2020) What is the impact of investing in power?

Energy Commission of Ghana (2016) 2016 Energy Supply and Demand Outlook for Ghana. 1-57

Gass V, Schmidt J, Strauss F, Schmid E (2013) Assessing the economic wind power potential in Austria. Energy Policy 53:323-330. https:// doi.org/10.1016/j.enpol.2012.10.079

Government of Ghana (1994) Ghana RAPID: effective population management for better quality of life

Government of Morroco (2019) Country results brief 2019

GWEC (2019a) Gwec | global wind report 2019

GWEC (2019b) Gwec report 2018. Wind Glob Council Energy

International T, Energy R, Irena A (2018) Renewable power generation costs in 2018

Iqbal W, Yumei H, Abbas Q, Hafeez M, Mohsin M, Fatima A, Jamali M, Jamali M, Siyal A, Sohail N (2019) Assessment of wind energy potential for the production of renewable hydrogen in Sindh 
Province of Pakistan. Processes 7. https://doi.org/10.3390/ pr7040196

Iram R, Zhang J, Erdogan S, Abbas Q, Mohsin M (2019) Economics of energy and environmental efficiency: evidence from OECD countries. Environ Sci Pollut Res 27:3858-3870. https://doi.org/10. 1007/s11356-019-07020-x

IRENA (2014)

IRENA (2017) Renewable energy auctions

Kang SH, Islam F, Kumar Tiwari A (2019) The dynamic relationships among $\mathrm{CO} 2$ emissions, renewable and non-renewable energy sources, and economic growth in India: evidence from timevarying Bayesian VAR model. Struct Chang Econ Dyn 50:90101. https://doi.org/10.1016/j.strueco.2019.05.006

Kazimierczuk AH (2019) Wind energy in Kenya: a status and policy framework review. Renew Sust Energ Rev 107:434-445. https:// doi.org/10.1016/j.rser.2018.12.061

Kilinc-ata N (2016) The evaluation of renewable energy policies across EU countries and US states: an econometric approach. Energy Sustain Dev 31:83-90. https://doi.org/10.1016/j.esd.2015.12.006

Madariaga A, Allain M (2018) Contingent coalitions in environmental policymaking: how civil society organizations influenced the Chilean renewable energy boom. Policy Stud J:1-28. https://doi. org $/ 10.1111 /$ psj. 12298

Marques C, Fuinhas A, Manso JRP (2010) Motivations driving renewable energy in European countries: a panel data approach. 38:68776885. https://doi.org/10.1016/j.enpol.2010.07.003

Mentis D, Hermann S, Howells M, Welsch M, Siyal SH (2015) Assessing the technical wind energy potential in Africa a GIS-based approach. Renew Energy 83:110-125. https://doi.org/10.1016/j.renene.2015. 03.072

Michael et al (2015) Alternatives no more. Solar and Wind

Mitchell (2019) Getting Energy Governance Right

Mohsin M, Abbas Q, Zhang J, Ikram M, Iqbal N (2019a) Integrated effect of energy consumption, economic development, and population growth on $\mathrm{CO} 2$ based environmental degradation: a case of transport sector. Environ Sci Pollut Res 26:32824-32835. https://doi. org/10.1007/s11356-019-06372-8

Mohsin M, Rasheed AK, Saidur R (2018a) Economic viability and production capacity of wind generated renewable hydrogen. Int J Hydrog Energy 43:2621-2630

Mohsin M, Zhou P, Iqbal N, Shah SAA (2018b) Assessing oil supply security of South Asia. Energy 155:438-447. https://doi.org/10. 1016/j.energy.2018.04.116

Mohsin M, Rasheed AK, Sun H, Zhang J, Iram R, Iqbal N, Abbas Q (2019b) Developing low carbon economies: an aggregated composite index based on carbon emissions. Sustain Energy Technol Assessments 35:365-374. https://doi.org/10.1016/j.seta.2019.08. 003

MohsinM, Zhang J, Saidur R, Sun H, Sait SM (2019c) Economic assessment and ranking of wind power potential using fuzzy-TOPSIS approach. Environ Sci Pollut Res 26:22494-22511. https://doi. org/10.1007/s11356-019-05564-6

Morris BC, Pehnt M (n.d.) THE GERMAN

OECD (2019) Financing climate futures rethinking infrastructure achieving clean energy access in sub-Saharan Africa Jan Corfee-Morlot (3Cs). James Ogunleye and Famous Ayeni (Carbon Limits Nigeria), Paul Parks

Ogbe W, Ogbe W (2018) Determinants of renewable energy growth in sub-Saharan Africa. https://doi.org/10.1016/j.energy.2018.05.068
Ogura Y (2020) Policy as a "porter" of RE component export or import? Evidence from PV/wind energy in OECD and BRICS. Energy Econ 86:104630. https://doi.org/10.1016/j.eneco.2019.104630

Panse R, Kathuria V (2016) Role of policy in deployment of wind energy: evidence across states of India. Renew Sust Energ Rev 53:422-432. https://doi.org/10.1016/j.rser.2015.08.056

Paper IW (2005) Transmission issues associated with renewable energy in Texas informal white paper

Renewable I, Agency E (2018) Planning and prospects for renewable power: west Africa

RENEWABLE ENERGY ACT 2011 (ACT 832).pdf(2018) L a z a r d' $\mathrm{s} 1 \mathrm{e}$ velized cos to fenergy an ly s is - version 12.0.0-19 Calculator_Levelized_Cost of Electricity_And FIT_Comparison_V1

Rocco MV, Tonini F, Fumagalli EM, Colombo E (2020) Electrification pathways for Tanzania: implications for the economy and the environment. J Clean Prod 121278:121278. https://doi.org/10.1016/j. jclepro.2020.121278

Sack B (2000) Does the fed act gradually? A VAR analysis. J Monet Econ 46:229-256. https://doi.org/10.1016/S0304-3932(00)00019-2

SEWEA (2019) South Africa's utility-scale wind \& re industry Key data as at March 2019. 1-2

Shiu A, Lam P (2004) Electricity consumption and economic growth in China. Renewable and Sustainable Energy Reviews 32:47-54

Shrimali G, Lynes M, Indvik J (2015) Wind energy deployment in the U.S: an empirical analysis of the role of federal and state policies. Renew Sust Energ Rev 43:796-806. https://doi.org/10.1016/j.rser. 2014.11.080

Stigka EK, Paravantis JA, Mihalakakou GK (2014) Social acceptance of renewable energy sources: a review of contingent valuation applications. Renew Sust Energ Rev 32:100-106. https://doi.org/10.1016/ j.rser.2013.12.026

Sun H, Ikram M, Mohsin M, Abbas Q (2019) Energy security and environmental efficiency: evidence from OECD countries. Singapore Econ Rev:1-18. https://doi.org/10.1142/S0217590819430033

Sun H, Mohsin M, Alharthi M,Abbas Q (2020a) Measuring environmental sustainability performance of South Asia. J Clean Prod 251: 119519. https://doi.org/10.1016/j.jclepro.2019.119519

Sun L, Qin L, Taghizadeh-Hesary F, Zhang J, Mohsin M, Chaudhry IS (2020b) Analyzing carbon emission transfer network structure among provinces in China: new evidence from social network analysis. Environ Sci Pollut Res. https://doi.org/10.1007/s11356-02008911-0

Thapar S, Sharma S, Verma A (2018) Key determinants of wind energy growth in India: analysis of policy and non-policy factors. Energy Policy 122:622-638. https://doi.org/10.1016/j.enpol.2018.08.004

World Energy Model Documentation (2019)

Yang C, Ge Z (2018) Dynamic feed-in tariff pricing model of distributed photovoltaic generation in China. Energy Procedia 152:27-32. https://doi.org/10.1016/j.egypro.2018.09.054

Yin H, Powers N (2010) Do state renewable portfolio standards promote in-state renewable generation <. Energy Policy 38:1140-1149. https://doi.org/10.1016/j.enpol.2009.10.067

Zhao X, Li S, Zhang S, Yang R, Liu S (2020) The effectiveness of China â€TM s wind power policy: an empirical analysis. Energy Policy 95: 269-279. https://doi.org/10.1016/j.enpol.2016.04.050

Publisher's note Springer Nature remains neutral with regard to jurisdictional claims in published maps and institutional affiliations. 